\title{
Possible Duplicities of Five Asteroids
}

\author{
Isao Satō ${ }^{1}$, Hiromi Hamanowa ${ }^{2}$, Hiroyuki Tomioka ${ }^{3}$, Sadaharu Uehara ${ }^{4}$ \\ ${ }^{1}$ Nihon University, Sakata, Yamagata, Japan \\ ${ }^{2}$ Hamanowa Astronomical Observatory, Motomiya, Fukushima, Japan \\ ${ }^{3}$ Hitachi, Ibaraki, Japan \\ ${ }^{4}$ KEK, Tsukuba, Ibaraki, Japan \\ Email: satoisao@nifty.com, hamaten@poplar.ocn.ne.jp, tomi-01@sea.plala.or.jp, \\ uehara@post.kek.jp
}

Received 10 May 2015; accepted 25 September 2015; published 28 September 2015

Copyright (C) 2015 by authors and Scientific Research Publishing Inc.

This work is licensed under the Creative Commons Attribution International License (CC BY). http://creativecommons.org/licenses/by/4.0/

(c) (i) Open Access

\begin{abstract}
Some evidences of possible duplicities of five asteroids are presented. A satellite of (279) Thule was convincingly detected by a stellar occultation on 2008 April 3 by Thule and also from follow-up light curve observations. The orbital period of the satellite is 3.007 or 6.014 days, and the minimum diameter is estimated to be $52 \mathrm{~km}$. A satellite of (324) Bamberga was detected by secondary drops of the light curve in 2007. The rotation period of the primary is 1.22625 days, and the revolution period of the secondary is $\mathbf{3 . 0 0}$ or 6.00 days. Presumed contact duplicity of the main body of the L4 Trojan (624) Hektor was detected by a stellar occultation by Hektor on 2008 January 24. A possible satellite of (657) Gunlöd was suggested from a secondary occultation by Gunlöd on 2008 November 29. The minimum of the diameter is $7 \mathrm{~km}$. A possible satellite of (739) Mandeville was suggested by stellar occultation observations on 1980 December 10.
\end{abstract}

\section{Keywords}

Asteroid, Occultation, Light Curve, Satellite, Binary

\section{Introduction}

Since the first discovery of Dactyl, a satellite of (243) Ida, by the Galileo spacecraft in 1993, several hundreds of satellites of asteroids have been detected by various means, such as asteroidal occultations, light curve observations, radar observations, and spacecraft encounters. Discovery of a satellite of an asteroid provides a total mass of the binary system from the third law of Kepler if its evolution period and semi-major axis of the orbit are obtained. We present some evidence of the duplicities of five asteroids detected in Japan through occultation observations.

*Corresponding author. 


\section{Satellite of (279) Thule}

\subsection{Stellar Occultation on 2008 April 3}

The asteroid (279) Thule was discovered by J. Palisa in 1888. The semi-major axis of its orbit is 4.27 au, the eccentricity of the orbit is 0.01 , and the revolution period is 8.83 years which is within the mean motion resonance of 4:3 with Jupiter. Asteroids with this resonance are part of a group called the Thule group. The other members of the Thule group known thus far are (185290) 2006 UB219 and (186024) 2001 QG207.Thule is a D-type asteroid [1].

The occultation of the star TYC 497200415 by (279) Thule, the first observed stellar occultation by Thule, was observed on 2008 April 3 from four sites in Japan. The event was predicted by Satō (Figure 1). The position of the occulted star is $\alpha_{2000}=13 \mathrm{~h} 31 \mathrm{~m} 32.3082 \pm 0.020 \mathrm{~s}, \delta_{2000}=-06^{\circ} 59^{\prime} 53^{\prime \prime} .701 \pm 0.022$, and the brightness of the star is $\mathrm{m}_{\mathrm{v}}=10.82$. The assumed diameter of Thule is $127 \mathrm{~km}$ and the predicted extinction would be 3.7 mag for 8.6 seconds. The occultation track would go through Kanto and Chubu districts of Japan. The observation results are listed in Table 1 . Three chords among four are timed by video with GPS clock, and one is visual.

Revealed occultation cross section is $(126 \pm 1 \mathrm{~km}) \times(123 \pm 7 \mathrm{~km})$, the position angle of the ellipse is $80^{\circ} \pm$ $129^{\circ}$ (Figure 2). Three chords by Yanagida Astronomical Observatory, Hideo Takashima, and Hideyoshi Karasaki are consistent with an ellipse of the primary, but the chord by Hiroyuki Tomioka is not coincident with it. This specific observation was made with GPS time-inserted video, hence the observation must be considered reliable. The extinction suggests a possible previously unknown satellite with diameter of $52 \mathrm{~km}$. The following-up light curve observations of Thule was obtained after the occultation.

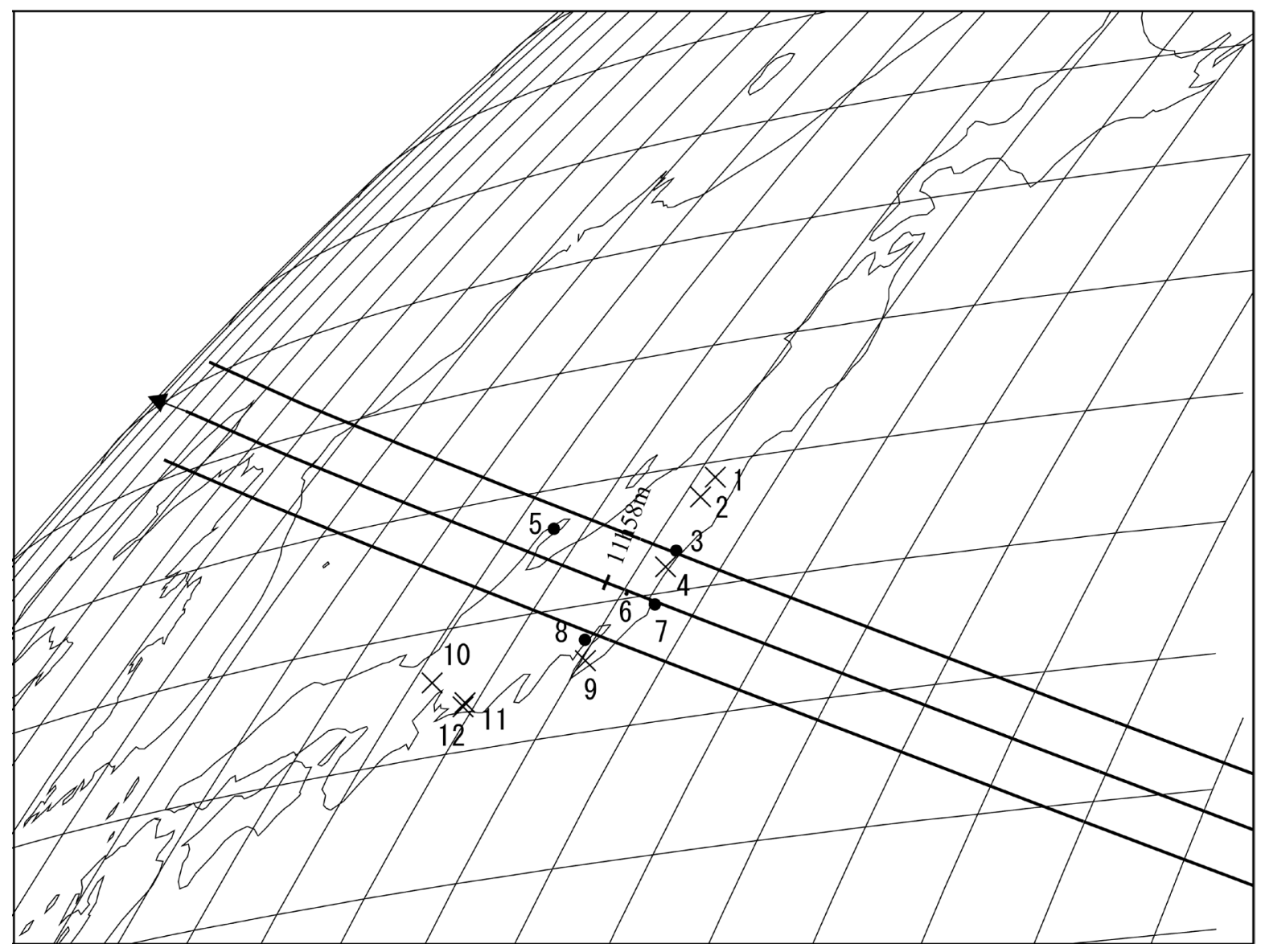

Figure 1. Occultation track and locations of observers of the occultation of TYC 497200415 by (279) Thule on 2008 April 3. The black circles $(\# 3,5,7,8)$ are successfully times sites and the crosses $(\# 1,2,4,9,10,11,12)$ are places where no occultation was observed. 
Table 1. Observationsdata of the occultation of TYC 497200415 by (279) Thule on 2008 April 3. Geodetic datum is WGS84.

\begin{tabular}{|c|c|c|c|c|c|c|c|c|c|}
\hline No. & observer & location & longitude & latitude & height & telescope & method & phen & UTC \\
\hline 1 & Hikaru Satō & $\begin{array}{l}\text { Fukushima, } \\
\text { Fukushima, Japan }\end{array}$ & $\mathrm{E} 140^{\circ} 29^{\prime} 25.3^{\prime \prime}$ & N37 $44^{\prime} 35.9^{\prime \prime}$ & $90 \mathrm{~m}$ & $\begin{array}{r}16 \mathrm{~cm} \mathrm{~N} \\
\mathrm{~F}=3.3\end{array}$ & $\begin{array}{l}\text { GHS, } \\
\text { TiVi } \\
\text { video }\end{array}$ & & no occultation \\
\hline 2 & $\begin{array}{l}\text { Hamanowa } \\
\text { Observatory }\end{array}$ & $\begin{array}{c}\text { Koriyama, } \\
\text { Fukushima, Japan }\end{array}$ & E140 25'48.4" & N37²2 $37.7^{\prime \prime}$ & $260 \mathrm{~m}$ & $\begin{array}{c}40 \mathrm{~cm} \mathrm{~N}, \\
\mathrm{~F}=4.5\end{array}$ & $\begin{array}{l}\text { GHS } \\
\text {,TiVi, } \\
\text { video }\end{array}$ & & no occultation \\
\hline 3 & $\begin{array}{l}\text { Kazuyuki } \\
\text { Shinozaki }\end{array}$ & $\begin{array}{l}\text { Takahagi, Ibaraki, } \\
\text { Japan }\end{array}$ & E14040'29.4" & N36 $42^{\prime} 19.4^{\prime \prime}$ & $40 \mathrm{~m}$ & $\begin{array}{c}35 \mathrm{~cm} \mathrm{SC}, \\
F=11\end{array}$ & $\begin{array}{l}\text { GPS, } \\
\text { visual }\end{array}$ & & no occultation \\
\hline 4 & $\begin{array}{l}\text { Hiroyuki } \\
\text { Tomioka }\end{array}$ & $\begin{array}{l}\text { Hitachi, } \\
\text { Ibaraki, } \\
\text { Japan }\end{array}$ & $\mathrm{E} 140^{\circ} 41^{\prime} 09^{\prime \prime}$ & N36 $38^{\circ} 33^{\prime \prime}$ & $33 \mathrm{~m}$ & $30 \mathrm{~cm} \mathrm{C}$ & $\begin{array}{l}\text { GHS, } \\
\text { TiVi, } \\
\text { video }\end{array}$ & $2 \mathrm{D}$ & $\begin{array}{c}11 \mathrm{~h} 57 \mathrm{~m} \\
57.90 \mathrm{~s} \pm 0.03 \mathrm{~s}\end{array}$ \\
\hline & & & & & & & & $2 \mathrm{R}$ & $\begin{array}{c}11 \text { h } 58 \mathrm{~m} \\
01.37 \mathrm{~s} \pm 0.03 \mathrm{~s}\end{array}$ \\
\hline 5 & $\begin{array}{c}\text { Akira } \\
\text { Tsuchikawa }\end{array}$ & $\begin{array}{c}\text { Yanagida, } \\
\text { Ishikawa, Japan }\end{array}$ & E13708'13.4" & $\mathrm{N} 37^{\circ} 20^{\prime} 04.1^{\prime \prime}$ & $200 \mathrm{~m}$ & $60 \mathrm{~cm} \mathrm{C}$ & $\begin{array}{l}\text { TEL, } \\
\text { video }\end{array}$ & 1D & $\begin{array}{c}11 \mathrm{~h} 58 \mathrm{~m} \\
02.50 \mathrm{~s} \pm 0.03 \mathrm{~s}\end{array}$ \\
\hline & & & & & & & & $1 \mathrm{R}$ & $\begin{array}{c}11 \mathrm{~h} 58 \mathrm{~m} \\
10.09 \mathrm{~s} \pm 0.03 \mathrm{~s}\end{array}$ \\
\hline 6 & $\begin{array}{l}\text { Sadaharu } \\
\text { Uehara }\end{array}$ & $\begin{array}{l}\text { Tsukuba, Ibaraki, } \\
\text { Japan }\end{array}$ & E1400'04.2" & N36이'11.2" & $30 \mathrm{~m}$ & $\begin{array}{c}20 \mathrm{~cm} \mathrm{~N}, \\
\mathrm{~F}=4\end{array}$ & & & cloudy \\
\hline 7 & $\begin{array}{c}\text { Hideo } \\
\text { Takashima }\end{array}$ & $\begin{array}{c}\text { Kashiwa, Chiba, } \\
\text { Japan }\end{array}$ & E140 $58^{\prime} 07^{\prime \prime}$ & N35 $49^{\prime} 53^{\prime \prime}$ & $28 \mathrm{~m}$ & $\begin{array}{c}20 \mathrm{~cm} \mathrm{~S} \\
\mathrm{~F}=2\end{array}$ & $\begin{array}{l}\text { GHS, } \\
\text { TiVi, } \\
\text { video }\end{array}$ & $1 \mathrm{D}$ & $\begin{array}{c}11 \mathrm{~h} 57 \mathrm{~m} \\
56.13 \mathrm{~s} \pm 0.04 \mathrm{~s}\end{array}$ \\
\hline \multirow{3}{*}{8} & \multirow{3}{*}{$\begin{array}{l}\text { Hideyoshi } \\
\text { Karasaki }\end{array}$} & \multirow{3}{*}{$\begin{array}{l}\text { Nerima, } \\
\text { Tokyo, } \\
\text { Japan }\end{array}$} & \multirow{3}{*}{ E1394'00.3" } & \multirow{3}{*}{ N35 44'25.4" } & \multirow{3}{*}{$46 \mathrm{~m}$} & \multirow{3}{*}{$20.3 \mathrm{~cm} \mathrm{SC}$} & \multirow{3}{*}{$\begin{array}{l}\text { TEL, } \\
\text { TiVi, } \\
\text { video }\end{array}$} & $1 \mathrm{R}$ & $\begin{array}{c}11 \mathrm{~h} 58 \mathrm{~m} \\
02.24 \mathrm{~s} \pm 0.04 \mathrm{~s}\end{array}$ \\
\hline & & & & & & & & 1D & $\begin{array}{c}11 \mathrm{~h} 57 \mathrm{~m} \\
58.6 \mathrm{~s} \pm 0.6 \mathrm{~s}\end{array}$ \\
\hline & & & & & & & & $1 \mathrm{R}$ & $\begin{array}{c}11 \mathrm{~h} 57 \mathrm{~m} \\
59.9 \mathrm{~s} \pm 0.6 \mathrm{~s}\end{array}$ \\
\hline 9 & Mamoru Urabe & $\begin{array}{c}\text { Kamogawa, } \\
\text { Chiba, } \\
\text { Japan }\end{array}$ & E140 $06^{\prime} 05^{\prime \prime}$ & N3506'35" & $8 \mathrm{~m}$ & $\begin{array}{c}30 \mathrm{~cm} \mathrm{~N}, \\
F=4\end{array}$ & $\begin{array}{l}\text { TEL, } \\
\text { video }\end{array}$ & & no occultation \\
\hline 10 & Minoru, Owada & $\begin{array}{l}\text { Hamamatsu, } \\
\text { Shizuoka, } \\
\text { Japan }\end{array}$ & E137 $44^{\prime} 08.0^{\prime \prime}$ & $\mathrm{N} 34^{\circ} 42^{\prime} 02.5^{\prime \prime}$ & $8 \mathrm{~m}$ & $\begin{array}{c}10 \mathrm{~cm} \mathrm{R}, \\
\mathrm{F}=4\end{array}$ & $\begin{array}{l}\text { GHS, } \\
\text { TiVi, } \\
\text { video }\end{array}$ & & no occultation \\
\hline 11 & Hisashi Suzuki & $\begin{array}{l}\text { Hamamatsu, } \\
\text { Shizuoka, } \\
\text { Japan }\end{array}$ & $\mathrm{E} 137^{\circ} 42^{\prime} 48.4^{\prime \prime}$ & $\mathrm{N} 34^{\circ} 45^{\prime} 53.8^{\prime \prime}$ & $50 \mathrm{~m}$ & $\begin{array}{c}25 \mathrm{~cm} \mathrm{R} \\
\mathrm{F}=5\end{array}$ & $\begin{array}{l}\text { GHS, } \\
\text { TiVi, } \\
\text { video }\end{array}$ & & no occultation \\
\hline 12 & Akira Arai & $\begin{array}{l}\text { Inabe, } \\
\text { Mie, } \\
\text { Japan }\end{array}$ & E136 31'24.3" & N35 $10^{\prime} 14.6^{\prime \prime}$ & $187 \mathrm{~m}$ & $\begin{array}{c}35.5 \mathrm{~cm} \mathrm{SC}, \\
\mathrm{F}=11\end{array}$ & $\begin{array}{l}\text { GHS, } \\
\text { TiVi, } \\
\text { video }\end{array}$ & & no occultation \\
\hline
\end{tabular}

\subsection{Light Curve Observations in 2008}

A light curve observation was obtained at Hamanowa Observatory during 13 nights from 2008 April 8 to May 6. Figure 3 shows a total combined light curve. Four instances of secondary drops are seen in the light curve. The Light curve shows at rotation period of $7 \mathrm{~h} 26 \mathrm{~m} 24 \pm 1 \mathrm{~s}$, peak-to-peak amplitude of 0.081 mag with secondary drops of 0.1 mag. The result is coincident with the previous result of $7.44 \pm 0.05$ hours [2]. Figure 4 shows the light curves of four nights with secondary drops, 2008 April 6, 15, 30, and May 3. The secondary drops suggest a satellite with revolution period of 3.007 or 6.014 days. The assumed phase of the secondary drop at the time of the stellar occultation is coincident with the hypothesis that Tomioka's extinction occurred from a satellite with a diameter of $52 \mathrm{~km}$, namely, it is assumed that the possible satellite was during the partial phase of a mutual phenomenon. 


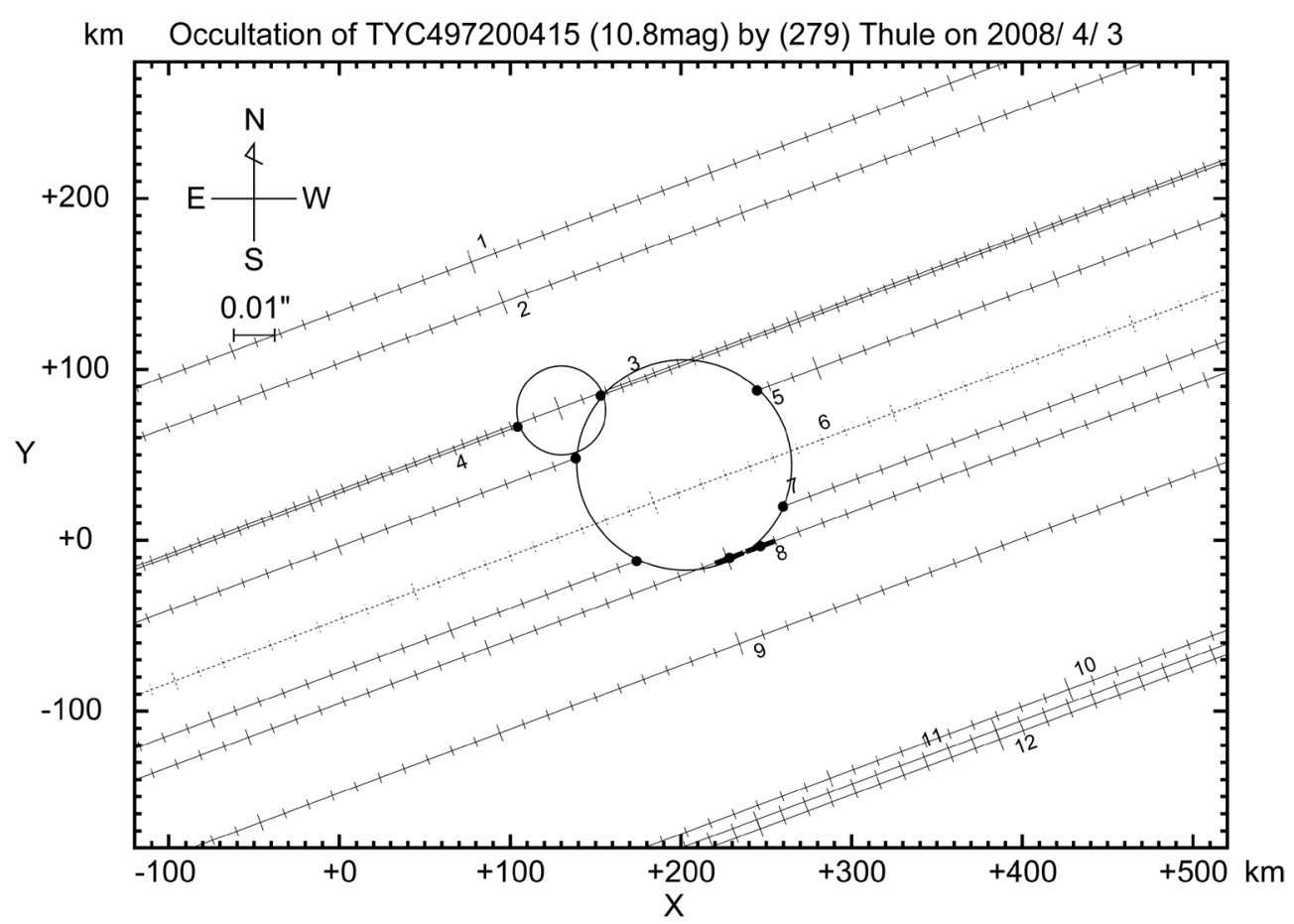

Figure 2. Result of the occultation of TYC 497200415 by (279) Thule on 2008 April 3. An ellipse of (126 $\pm 1 \mathrm{~km}) \times(123 \pm 7 \mathrm{~km})$ is fitted for the primary, and a circle of a diameter of $52 \mathrm{~km}$ is fitted for the satellite.

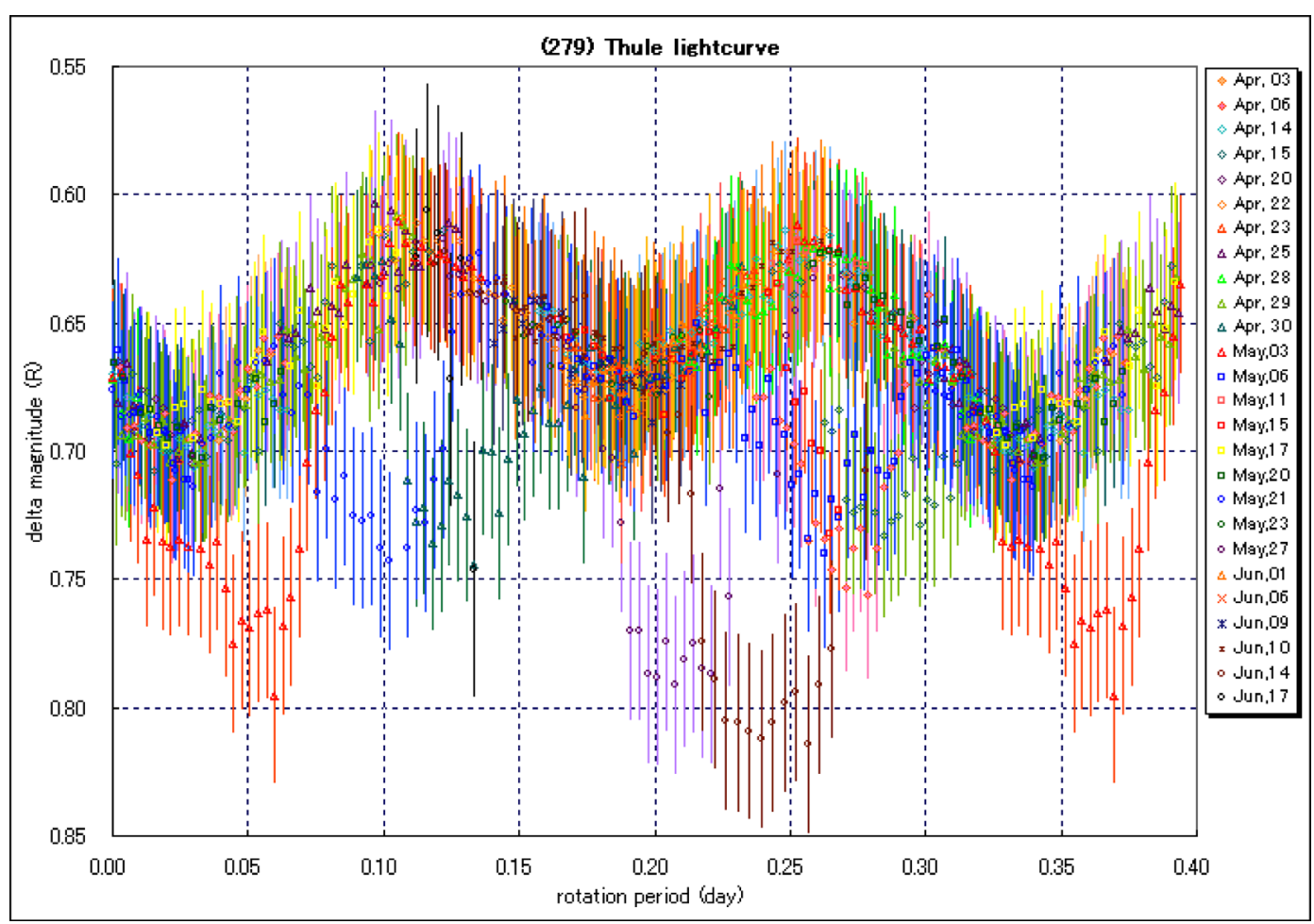

Figure 3. Composed light curve of (279) Thule from 2008 April 3 to May 6 at Hamanowa Astronomical Observatory. The main light curve is consistent with a period of $7.44 \pm 0.05$ hoursand a peak-to-peak amplitude of 0.081 mag. In addition to the main light curve, secondary drops are shown on four nights (April 6, 15, 30, and May 3). 


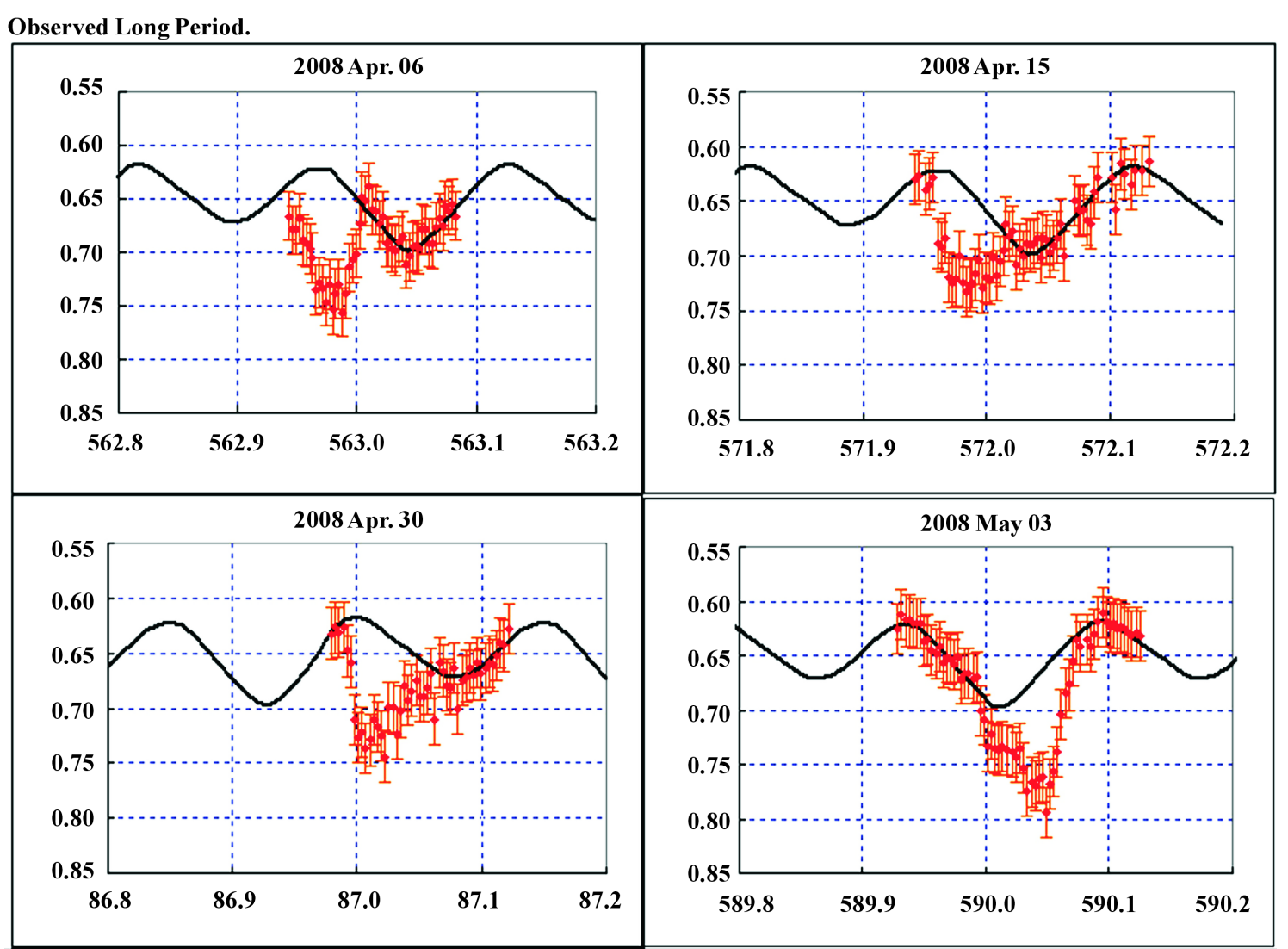

Figure 4. Detailed features of the light curves of (279) Thule on 2008 April 6, 15, 30, and May 3. Each figure shows a secondary drop on the main light curve. The period of the secondary drops is 3.007 or 6.014 days.

\section{Satellite of (324) Bamberga}

(324) Bamberga was discovered by J. Palisa in 1892. The planet is a main belt asteroid with a revolution period of 4.4 years. The first stellar occultation by (324) Bamberga was observed from the USA, Japan and China on 1987 December 8. The occultation cross section showed a diameter of $227.6 \pm 1.8 \mathrm{~km}$ [3].

The second event, the occultation of HIP059807 (7.3 mag) by Bamberga, was observed from five sites in Australia on 2007 April 20 (Table 2, Figure 5). The occultation cross section shows an ellipse of (231 $\pm 4 \mathrm{~km})$ $\times(211 \pm 12 \mathrm{~km}), \mathrm{P}=106^{\circ} \pm 8^{\circ}$. Hamanowa Observatory performed light curve observations just after the second event from 2007 April 23 to May 22. As a result, the amplitude is $0.084 \pm 0.0030$ mag during the rotation period of $29 \mathrm{~h} 27 \mathrm{~m} 27 \pm 3 \mathrm{~s}$ (Figure 6). Light curve observations were also obtained by [4]-[6]. The period is coincident with these results.

The light curve (Figure 6) also shows secondary drops on the three nights (2007 April 28, May 4 and 7). Expanded light curve from 2007 April 23 to May 8 (Figure 7) shows that the observations on the six nights (2007 April 23, 26, 27, 30, May 3, and 8) fit the shorter period (1.2274 days) sine curve but the observations on the three nights (2007 April 28, May 4 and 7) fit the long period (2.96 days) sine curve. This fact suggests an unknown satellite whose revolution period is 2.96 days.

From these two occultation cross sections and light curves, a 3-D model of Bamberga is reconstructed by the statistical inversion method [7]. The results are shown in Figure 8 and Figure 9. North and south pole is $(\lambda, \beta)=$ $\left(149^{\circ} \pm 11^{\circ},+68^{\circ} \pm 11^{\circ}\right)$ or $\left(329^{\circ} \pm 11^{\circ},-68^{\circ} \pm 11^{\circ}\right)$, lengths of the three principal axes are $(2 a, 2 b, 2 c)=(246.3$ $\pm 168.6 \mathrm{~km}) \times(228.3 \pm 9.5 \mathrm{~km}) \times(220.4 \pm 8.0 \mathrm{~km})$. Constructed cross sections are shown in Figure 10 and Figure 11.

\section{Duplicity of (624) Hektor}

The L4 Trojan (624) Hektor was discovered by A. Kopff in 1907. Hektor has a satellite S/2006 (624) 1 of diameter 


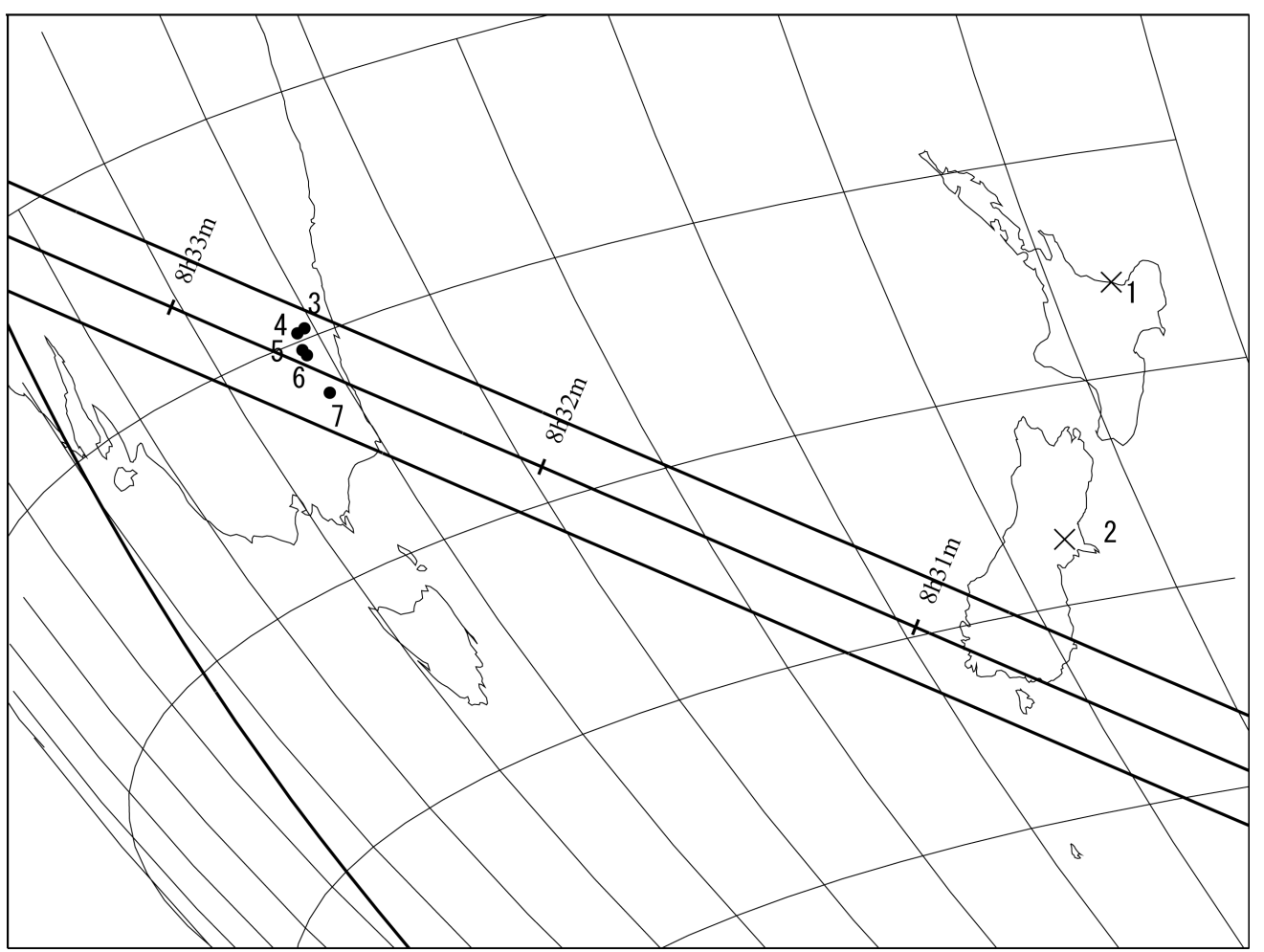

Figure 5. Occultation track and locations of the black circles observers of the occultation of HIP 059807 by (324) Bamberga on 2007 April 20. The black circles (\#3 - 7) are sites where the occultation was successfully timed and the crosses $(\# 1,2)$ are sites where no occultation occurred.

Table 2. Observation data of the occultation of HIP 59807 by (324) Bamberga on 2007 April 20. Geodetic datum is WGS84 [20].

\begin{tabular}{|c|c|c|c|c|c|c|c|c|c|}
\hline No. & Observer & location & longitude & latitude & height & telescope & method & phen & UTC \\
\hline 1 & D. Waton & $\begin{array}{c}\text { Whakatane, } \\
\text { NZ }\end{array}$ & E176 $51 ' 50.7 "$ & S3755'18.5" & $3 \mathrm{~m}$ & $20 \mathrm{~cm}$ & & & no occultation \\
\hline 2 & B. Loader & Darfiled, NZ & E17206'24.4" & $\mathrm{S}^{\prime} 3^{\circ} 28^{\prime} 52.9^{\prime \prime}$ & $210 \mathrm{~m}$ & $25 \mathrm{~cm}$ & & & no occultation \\
\hline \multirow[t]{2}{*}{3} & D. Gault & $\begin{array}{l}\text { Goulburn, } \\
\text { NSW, Aus }\end{array}$ & E149³8'29.4" & $\mathrm{S} 34^{\circ} 47^{\prime} 12.9^{\prime \prime}$ & $702 \mathrm{~m}$ & $20 \mathrm{~cm}$ & & $\mathrm{D}$ & $08 \mathrm{~h} 32 \mathrm{~m} 36.46 \mathrm{~s}$ \\
\hline & & & & & & & & $\mathrm{R}$ & $08 \mathrm{~h} 32 \mathrm{~m} 47.66 \mathrm{~s}$ \\
\hline \multirow[t]{2}{*}{4} & A. Brakel & $\begin{array}{l}\text { Gunning, } \\
\text { NSW, Aus }\end{array}$ & E149¹4'31.8" & $\mathrm{S} 34^{\circ} 49^{\prime} 58.5^{\prime \prime}$ & $620 \mathrm{~m}$ & $20 \mathrm{~cm}$ & & $\mathrm{D}$ & $\begin{array}{c}08 \mathrm{~h} 32 \mathrm{~m} \\
35.9 \mathrm{~s} \pm 0.6 \mathrm{~s}\end{array}$ \\
\hline & & & & & & & & $\mathrm{R}$ & $\begin{array}{c}08 \mathrm{~h} 32 \mathrm{~m} \\
49.1 \mathrm{~s} \pm 0.4 \mathrm{~s}\end{array}$ \\
\hline \multirow[t]{2}{*}{5} & M. Nelmes & $\begin{array}{c}\text { Spence, ACT, } \\
\text { Aus }\end{array}$ & E14903'30.6" & S35 $11 ' 39.8^{\prime \prime}$ & $702 \mathrm{~m}$ & $10 \mathrm{~cm}$ & & $\mathrm{D}$ & $\begin{array}{c}08 \mathrm{~h} 32 \mathrm{~m} \\
33.9 \mathrm{~s} \pm 0.3 \mathrm{~s}\end{array}$ \\
\hline & & & & & & & & $\mathrm{R}$ & $\begin{array}{c}08 \mathrm{~h} 32 \mathrm{~m} \\
48.2 \mathrm{~s} \pm 0.3 \mathrm{~s}\end{array}$ \\
\hline \multirow[t]{2}{*}{6} & P. Purcell & $\begin{array}{c}\text { Red Hill, ACT, } \\
\text { Aus }\end{array}$ & E1490'51.8" & S3519'30.6" & $733 \mathrm{~m}$ & $40 \mathrm{~cm}$ & & $\mathrm{D}$ & $\begin{array}{c}08 \mathrm{~h} 32 \mathrm{~m} \\
33.1 \mathrm{~s} \pm 0.6 \mathrm{~s}\end{array}$ \\
\hline & & & & & & & & $\mathrm{R}$ & $\begin{array}{c}08 \mathrm{~h} 32 \mathrm{~m} \\
47.73 \mathrm{~s} \pm 0.4 \mathrm{~s}\end{array}$ \\
\hline \multirow[t]{2}{*}{7} & David Herald & $\begin{array}{c}\text { Cooma, NSW, } \\
\text { Aus }\end{array}$ & E14909'44.8" & S36 $14^{\prime} 18.6^{\prime \prime}$ & $835 \mathrm{~m}$ & $20 \mathrm{~cm}$ & & $\mathrm{D}$ & 08 h $32 \mathrm{~m} 27.95 \mathrm{~s}$ \\
\hline & & & & & & & & $\mathrm{R}$ & $08 \mathrm{~h} 32 \mathrm{~m} 41.48 \mathrm{~s}$ \\
\hline
\end{tabular}




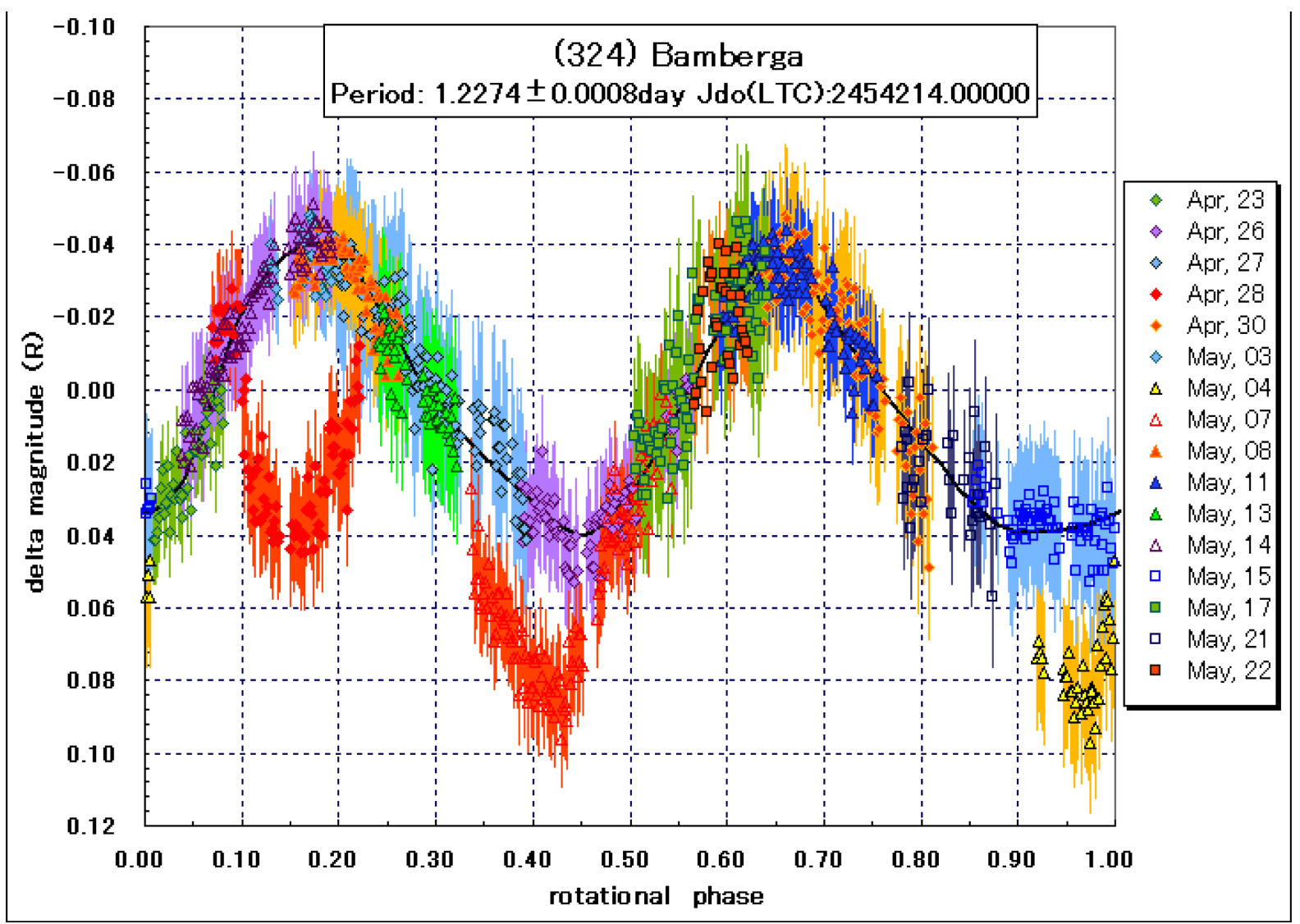

Figure 6. Composed light curve of (324) Bamberga from 2007 April 23 to May 22. The primary period is $1.2274 \pm 0.0008$ days. In addition to the primary period, secondary drops are shown on 2007 April 28, May 4 and 7.

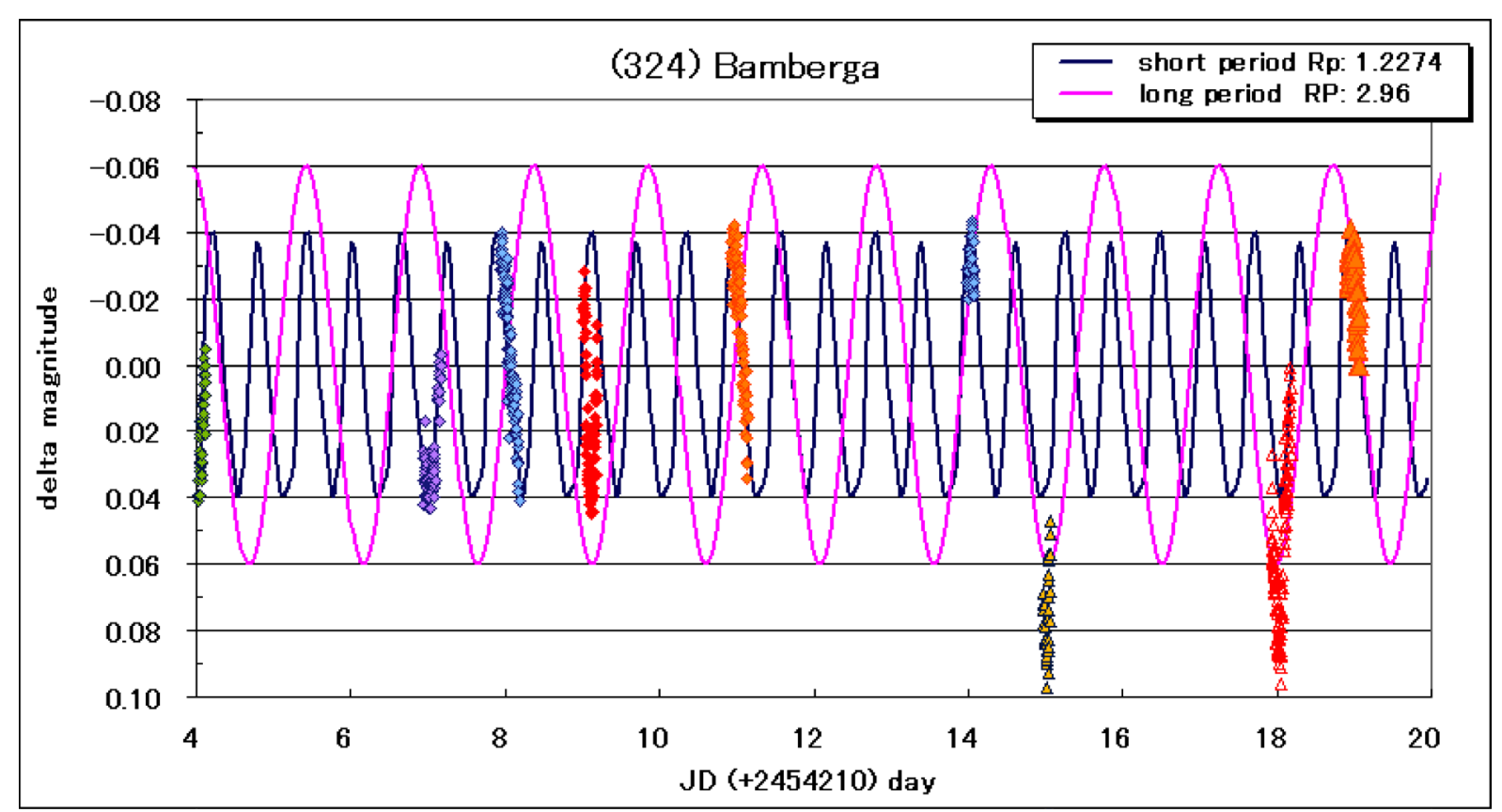

Figure 7. Expanded light curve of (324) Bamberga from 2007 April 23 to May 9. The short period sine curve (blue line) is 1.2274 days, and the long period sine curve (red line) is 2.96 days. The secondary drops on 2007 April 23, May 4 and 7 do not fall on the short period sine curve but are coinsident with the bottom of the long period sine curve. 
Probability distribution of orientation of spin vector of (324) Bamberga (ecliptic coordinates)

( occultation : $2007 / 4 / 20,1987 / 12 / 7$ )

( lightcurve : $2007,1978,1958$ )

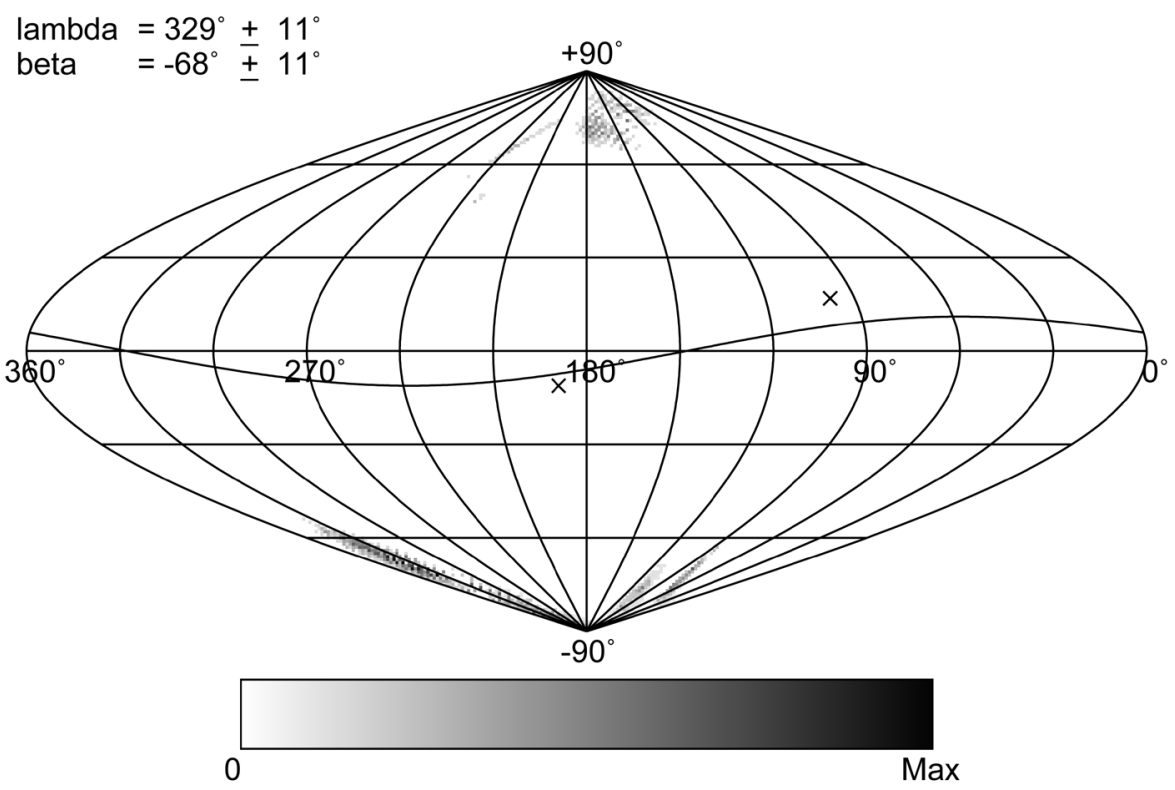

Figure 8. Probability distribution of the spin vector of (324) Bamberga. High probability regions are antipodal $(\lambda, \beta)=\left(149^{\circ} \pm 11^{\circ},+68^{\circ} \pm 11^{\circ}\right)$ (Ursa Major) or $(\lambda, \beta)=\left(329^{\circ} \pm 11^{\circ},-68^{\circ} \pm 11^{\circ}\right)$ (Eridanus). Two crosses indicate the positions of the occulted stars in 1987 and 2007 events, respectively.

Probability distribution of lengths of principal axes of (324) Bamberga

(occultation : 2007/4/20, 1987/12/7)

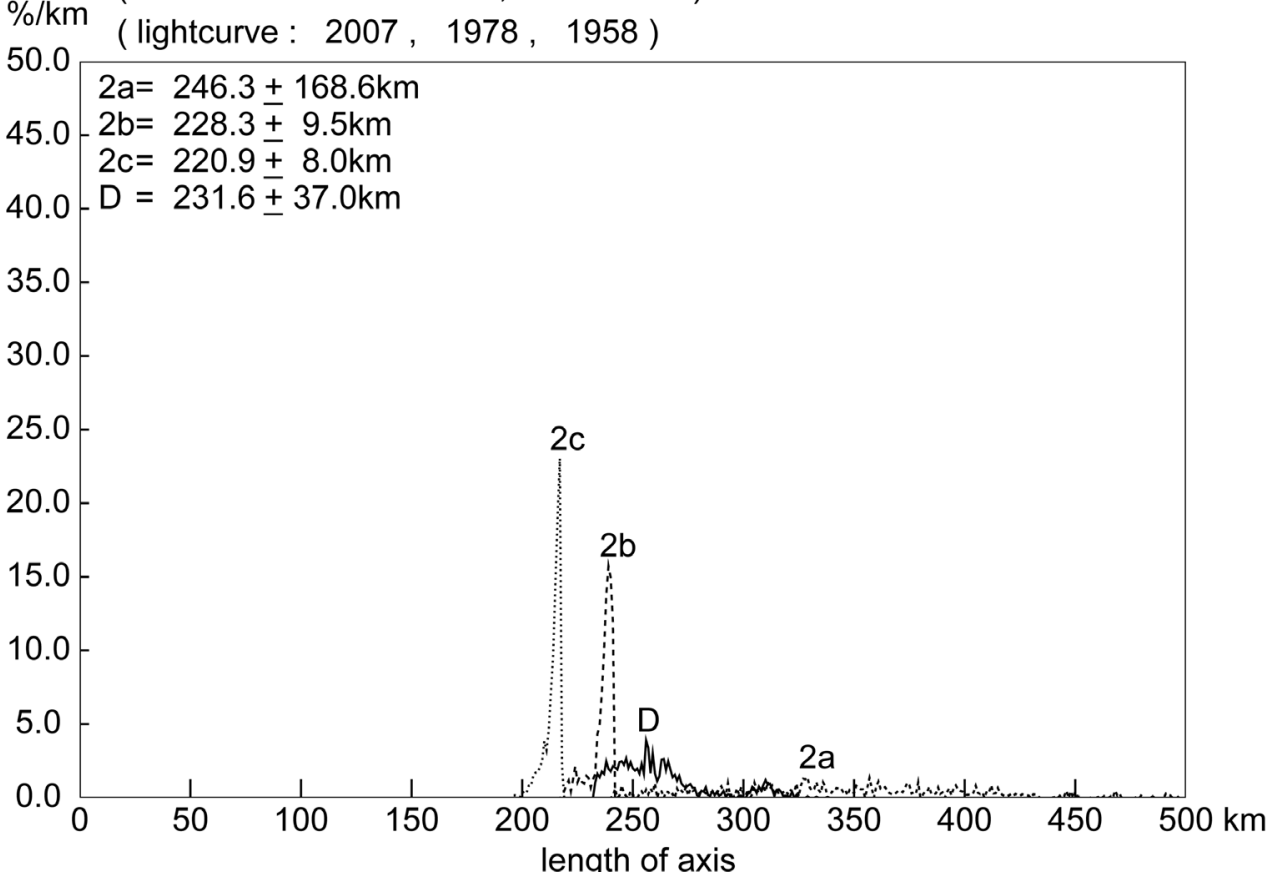

Figure 9. Probability distribution of the lengths of the three principal axes of (324) Bamberga. Since Bamberga is nearly a spheroid, the length of the longest axis a cannot be determined with sufficient accuracy. Assumed lengths are $(2 a, 2 b, 2 c)=(246.3 \pm 168.6 \mathrm{~km}) \times(228.3 \pm 9.5 \mathrm{~km}) \times(220.4 \pm 8.0 \mathrm{~km})$. 


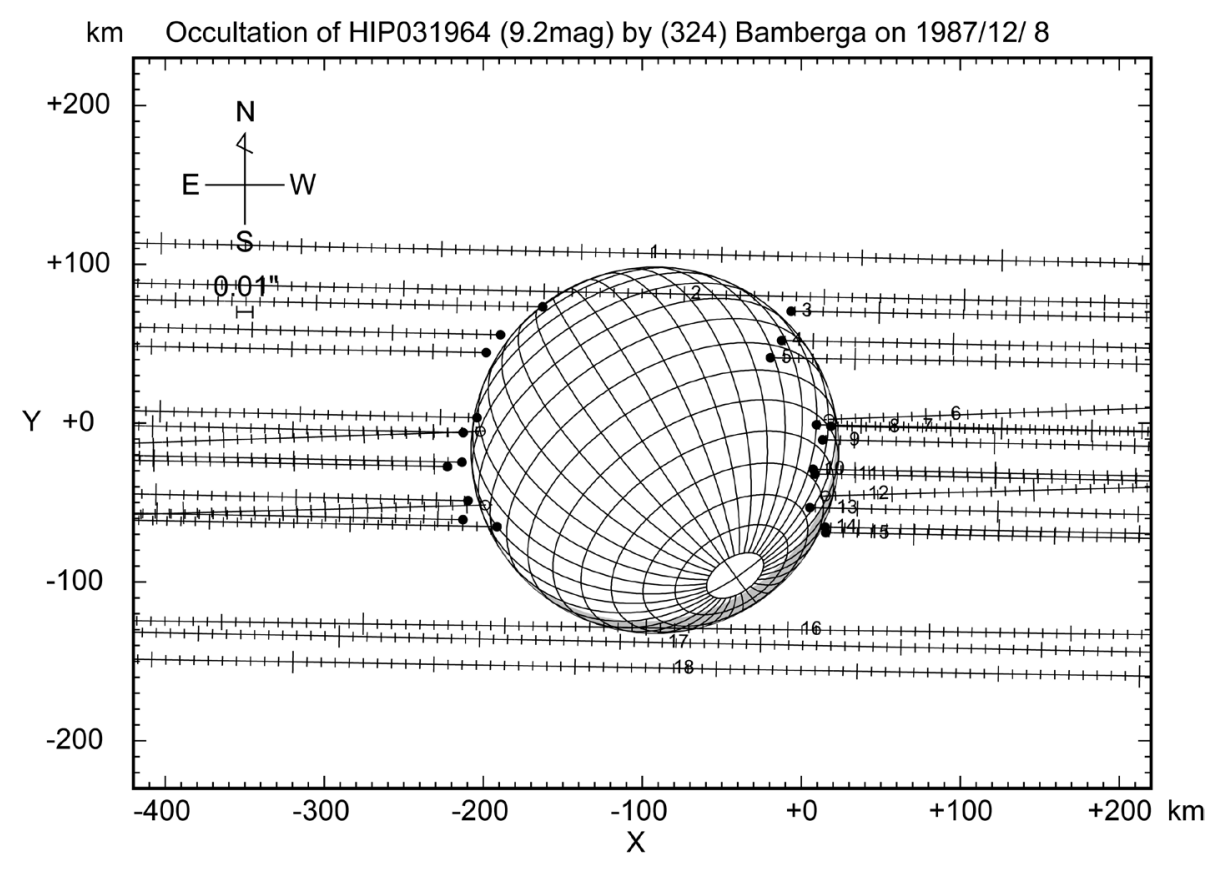

Figure 10. Reconstructed 3-D shape of (324) Bamberga during the occultation of HIP 031964 on 1987 December 8.

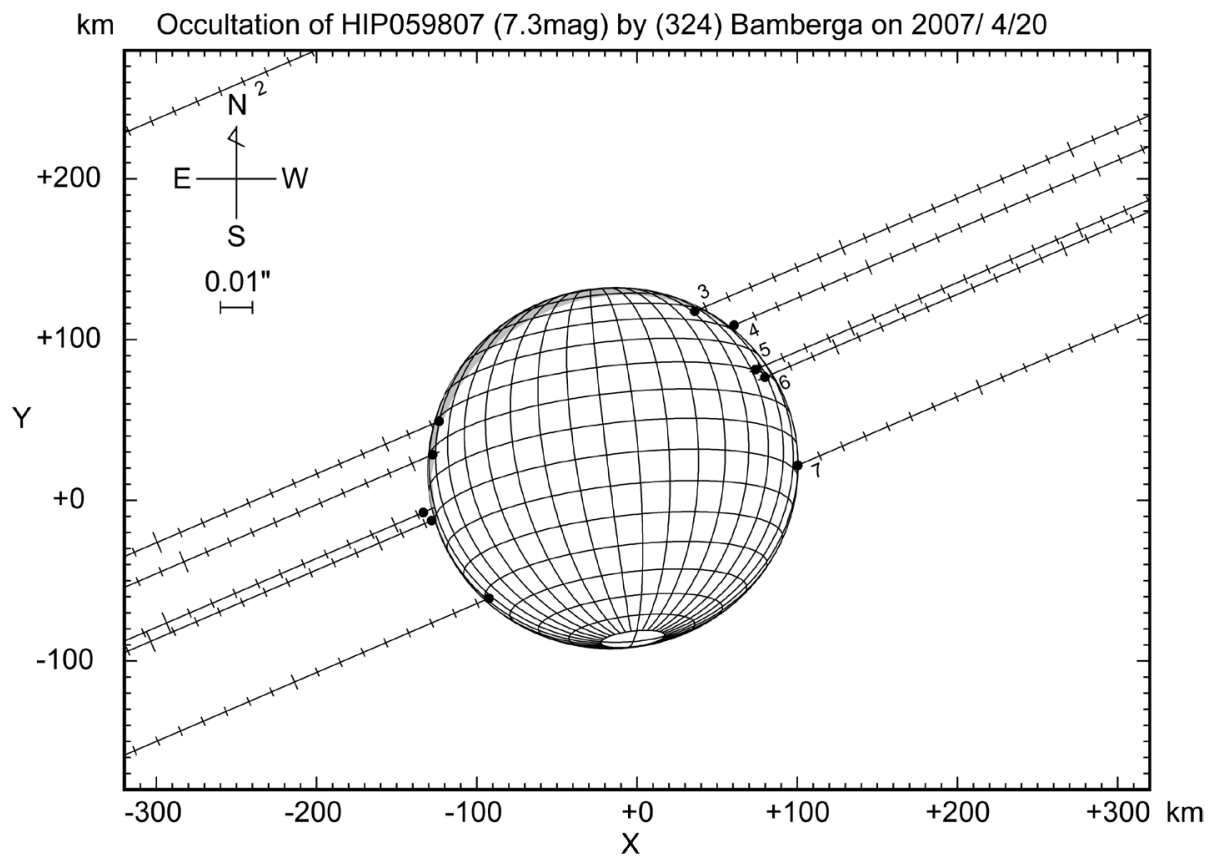

Figure 11. Reconstrunted 3-D shape of (324) Bamberga during the occultation of HIP 059807 on 2007 April 20.

$15 \mathrm{~km}$ [8]. The stellar occultation by (624) Hektor of TYC057700887 (10.1 mag) was observed from two sites in Japan on 2008 January 24 (Figure 12). This is the first stellar occultation observation to be observed by Hektor. Tomioka at Hitachi, Ibaraki, detected an extinction for 4.4 seconds by video with GPS clock. Uehara at Tsukuba, Ibaraki, observed two times extinction, 3.6 and 5.0 seconds, respectively, by visual (Table 3, Figure 13). His observation suggests the primary body is a close or contact binary. A possible unusual shape of the primary has been suggested by many authors [9]-[19]. 


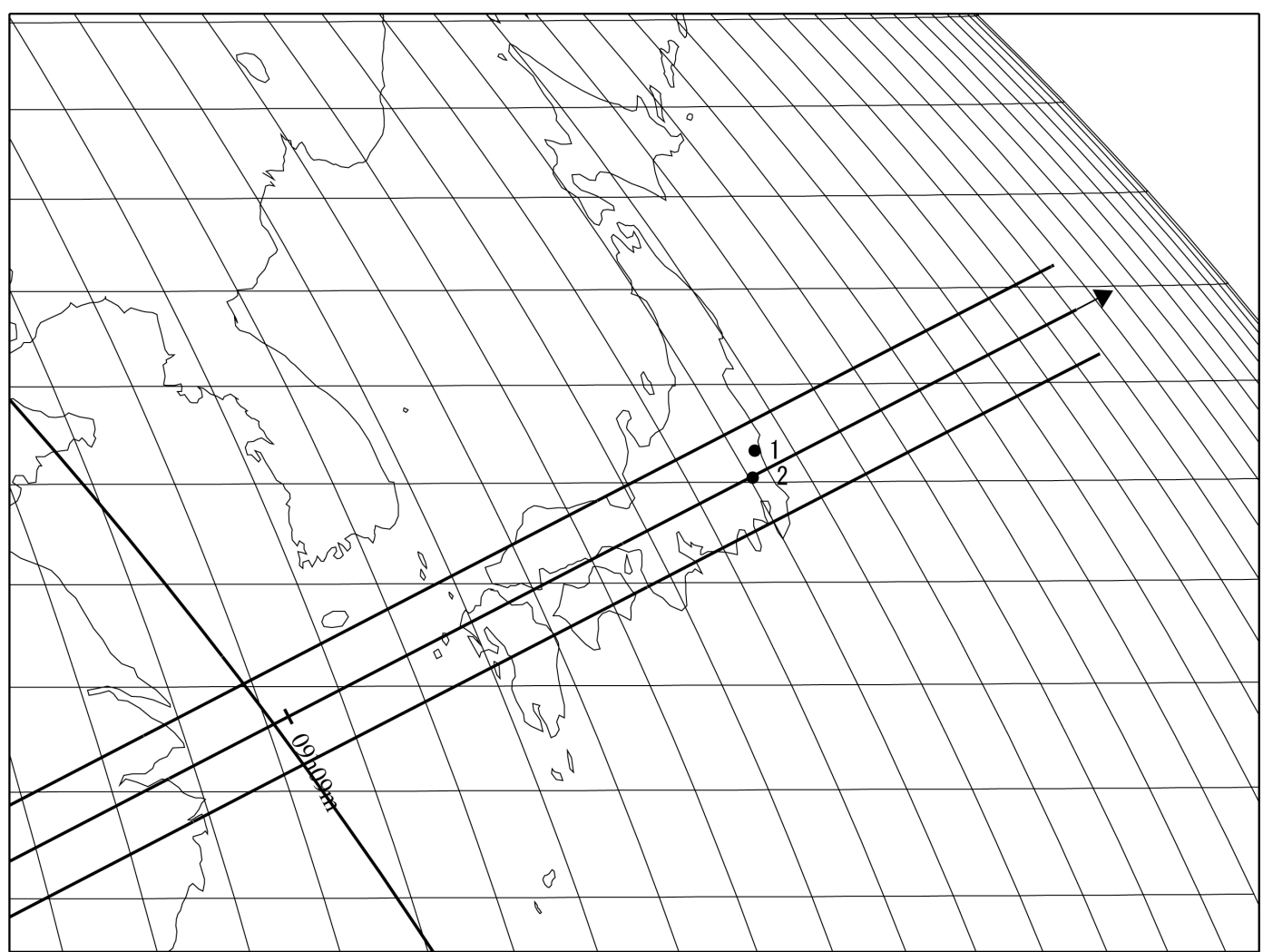

Figure 12. Occultation track and locations of observers of the occultation of TYC 057700817 by (624) Hektor on 2008 January 24. The black circles indicate sites where occultations were successfully timed.

Table 3. Observation data of the occultation of TYC 057700887 by (624) Hektor on 2008 January 24. Geodetic datum is WGS84.

\begin{tabular}{|c|c|c|c|c|c|c|c|c|c|}
\hline No. & observer & location & longitude & latitude & thgieh & telescope & method & phen & UTC \\
\hline 1 & $\begin{array}{l}\text { Hiroyuki } \\
\text { Tomioka }\end{array}$ & Hitachi, Ibaraki, Japan & $\mathrm{E} 140^{\circ} 41^{\prime} 09^{\prime \prime}$ & N36³8'33" & $33 \mathrm{~m}$ & $30 \mathrm{~cm} \mathrm{C}$ & GHS, TiVi, video & $\mathrm{D}$ & $\begin{array}{c}09 \mathrm{~h} 09 \mathrm{~m} \\
36.63 \mathrm{~s} \pm 0.05 \mathrm{~s}\end{array}$ \\
\hline \multirow{5}{*}{2} & \multirow{5}{*}{$\begin{array}{l}\text { Sadaharu } \\
\text { Uehara }\end{array}$} & \multirow{5}{*}{ Tsukuba, Ibaraki, Japan } & \multirow{5}{*}{$\mathrm{E} 140^{\circ} 07^{\prime} 04.2^{\prime \prime}$} & \multirow{5}{*}{ N36 $05^{\circ} 11.2^{\prime \prime}$} & \multirow{5}{*}{$30 \mathrm{~m}$} & \multirow{5}{*}{$\begin{array}{c}20 \mathrm{~cm} \mathrm{~N}, \\
F=4\end{array}$} & \multirow{5}{*}{ visual } & $\mathrm{R}$ & $\begin{array}{c}09 \mathrm{~h} 09 \mathrm{~m} \\
41.03 \mathrm{~s} \pm 0.05 \mathrm{~s}\end{array}$ \\
\hline & & & & & & & & $1 \mathrm{D}$ & $\begin{array}{c}09 \mathrm{~h} 09 \mathrm{~m} \\
28.8 \mathrm{~s} \pm 0.5 \mathrm{~s}\end{array}$ \\
\hline & & & & & & & & $1 \mathrm{R}$ & $\begin{array}{c}09 \mathrm{~h} 09 \mathrm{~m} \\
32.4 \mathrm{~s} \pm 0.3 \mathrm{~s}\end{array}$ \\
\hline & & & & & & & & $2 \mathrm{D}$ & $\begin{array}{c}09 \mathrm{~h} 09 \mathrm{~m} \\
35.2 \mathrm{~s} \pm 0.6 \mathrm{~s}\end{array}$ \\
\hline & & & & & & & & $2 \mathrm{R}$ & $\begin{array}{c}09 \mathrm{~h} 09 \mathrm{~m} \\
40.2 \mathrm{~s} \pm 0.4 \mathrm{~s}\end{array}$ \\
\hline
\end{tabular}

\section{Possible Satellite of (657) Gunlöd}

(657) Gunlöd was discovered by A. Kopff in 1908. The planet is a main belt asteroid with a revolution period of 4.22 years. The stellar occultation of UCAC2 43078953 (12.0 mag) by (657) Gunlöd was observed from three sites in Japan (Table 4, Figure 14) on 2008 November 29. Hiroyuki Tomioka at Hitachi, Ibaraki, detected a 3.5 second extinction by video with GPS clock. Akira Yaeza at Hitachi, Ibaraki, also observed a 4.6 seconds visual extinction.

Two chords are coincident with a circle with a cross section of a diameter $45 \pm 5 \mathrm{~km}$ compared with the assumed diameter of $42 \mathrm{~km}$. These extinctions were caused by the primary. On the other hand, a short extinction of for 0.7 second was detected at Hamanowa Observatory by video with GPS clock located about $100 \mathrm{~km}$ north of the occultation track of the primary (Figure 15). Compared with the predicted extinction of 2.9 mag for 4.4 


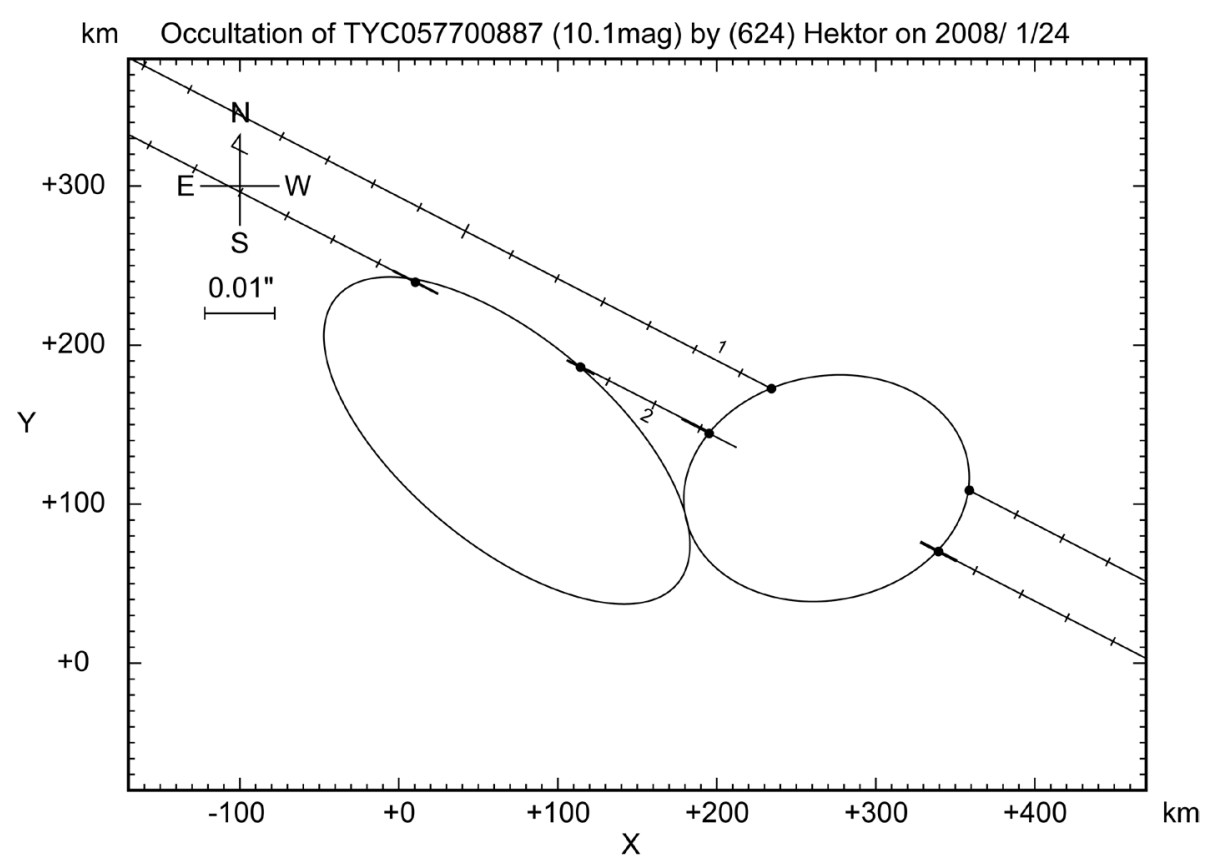

Figure 13. Result of the occultation of TYC 057700887 by (624) Hektor on 2008 January 24. Two extinctions were visually observed at \#2 site. Since the main body is assumed to be a contact binary, two contact ellipses of $(280 \times 130 \mathrm{~km})$ and $(181 \times 141 \mathrm{~km})$ are fitted.

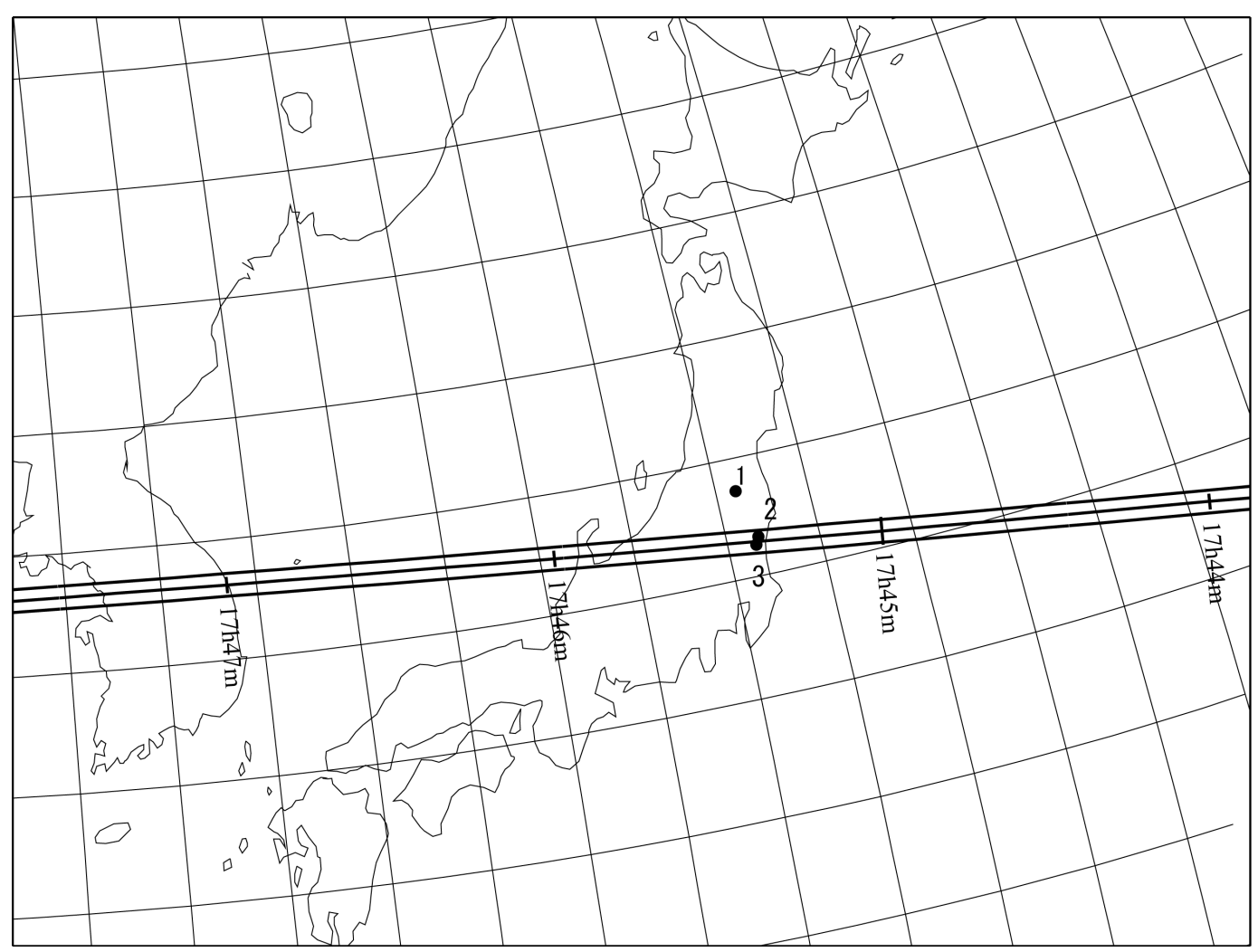

Figure 14. Occultation track and location of observers of the occultation of UCAC2 43078953 by (657) Gunl ōd on 2008 November 29. The black circles indicate location where occultations were successfully timed. Sites \#2 and 3 are where the star was occulted by the primary, and site \#1 is where the occultation was by a possible satellite. 


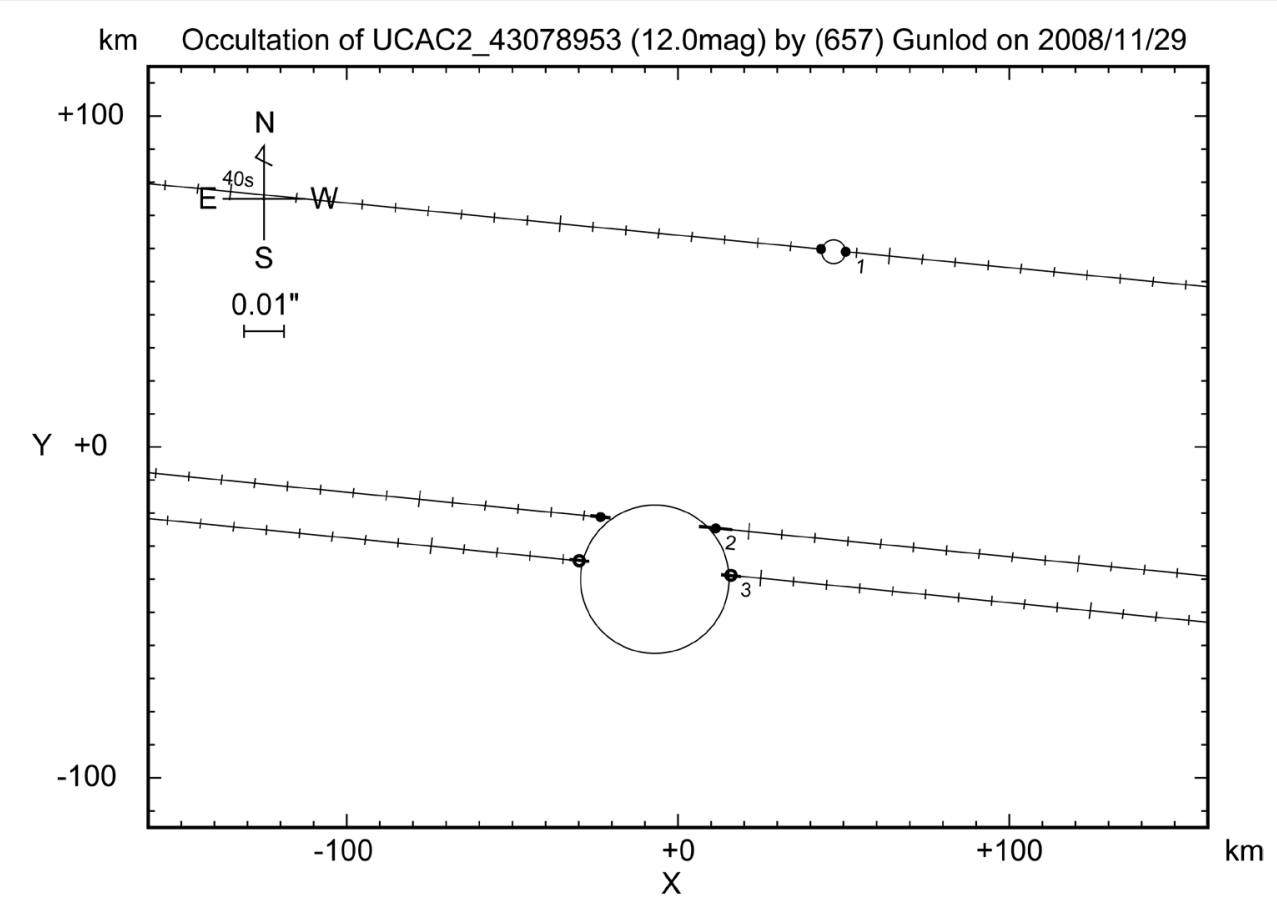

Figure 15. Result of the occultation of UCAC2 43078953 by (657) Gunlōd on 2008 November 29. Chord \#1 and \#2 are from timed video and \#3 is from a visual timing.

Table 4. Observation data of the occultation of UCAC2 43078953 by (657) Gunlöd on 2008 November 29. Geodetic datum is WGS84.

\begin{tabular}{|c|c|c|c|c|c|c|c|c|c|}
\hline No. & Observer & location & longitude & latitude & height & telescope & method & phen & UTC \\
\hline \multirow[t]{2}{*}{1} & $\begin{array}{l}\text { Hamanowa } \\
\text { Observatory }\end{array}$ & $\begin{array}{c}\text { Koriyama, } \\
\text { Fukushima, Japan }\end{array}$ & $\mathrm{E} 140^{\circ} 25^{\prime} 48.4^{\prime \prime}$ & N37²2'37.7" & $260 \mathrm{~m}$ & $\begin{array}{c}40 \mathrm{~cm} \mathrm{~N} \\
\mathrm{~F}=4.5\end{array}$ & GHS, TiVi, video & $\mathrm{D}$ & $\begin{array}{c}17 \mathrm{~h} 45 \mathrm{~m} \\
21.34 \mathrm{~s} \pm 0.06 \mathrm{~s}\end{array}$ \\
\hline & & & & & & & & & $\begin{array}{c}17 \mathrm{~h} 45 \mathrm{~m} \\
22.07 \mathrm{~s} \pm 0.06 \mathrm{~s}\end{array}$ \\
\hline \multirow[t]{2}{*}{2} & $\begin{array}{l}\text { Hiroyuki } \\
\text { Tomioka }\end{array}$ & $\begin{array}{l}\text { Hitachi, Ibaraki, } \\
\text { Japan }\end{array}$ & E14041'09" & N36³8'33" & $33 \mathrm{~m}$ & $30 \mathrm{~cm} \mathrm{C}$ & GHS, TiVi, video & $\mathrm{D}$ & $\begin{array}{c}1745 \mathrm{~m} \\
21.0 \mathrm{~s} \pm 0.5 \mathrm{~s}\end{array}$ \\
\hline & & & & & & & & $\mathrm{R}$ & $\begin{array}{c}17 \mathrm{~h} 45 \mathrm{~m} \\
24.5 \mathrm{~s} \pm 0.3 \mathrm{~s}\end{array}$ \\
\hline \multirow[t]{2}{*}{3} & Akira Yaeza & $\begin{array}{l}\text { Hitachi, Ibaraki, } \\
\text { Japan }\end{array}$ & E140 36'11" & N36³1'28" & $230 \mathrm{~m}$ & $\begin{array}{c}20 \mathrm{~cm} \mathrm{C} \\
133 \mathrm{x}\end{array}$ & TEL visual & $\mathrm{D}$ & $\begin{array}{c}17 \mathrm{~h} 45 \mathrm{~m} \\
25.4 \mathrm{~s} \pm 0.3 \mathrm{~s}\end{array}$ \\
\hline & & & & & & & & $\mathrm{R}$ & $\begin{array}{c}17 \mathrm{~h} 45 \mathrm{~m} \\
30.0 \mathrm{~s} \pm 0.3 \mathrm{~s}\end{array}$ \\
\hline
\end{tabular}

seconds, this extinction is possibly caused by an unknown satellite with a diameter of $7 \mathrm{~km}$. Another possible interpretation is that the occulted star is double.

\section{Possible Satellite of (739) Mandeville}

(739) Mandeville was discovered by J. H. Metcalf in 1913. The planet is a main belt asteroid with a revolution period of 4.53 years. The stellar occultation of PPM177093 = HIP052360 (9.4 mag) by (739) Mandeville was observed from two sites in Japan on 1980 December 10 (Table 5, Figure 16). The event was the first ever successfully observed asteroid occultation from Japan. Miyoshi Ida at Ohmi-hachiman, Shiga, observed an extinction for five or six second visually with $6.5 \mathrm{~cm}$ telescope, but he failed to record his voice, as a result the time and duration of the event are uncertain. The extinction corresponds to a chord from 69 to $83 \mathrm{~km}$. On the other hands, Toshio Hirose at Yaita, Tochigi, visually observed an extinction of 2.1 seconds also with $6.5 \mathrm{~cm}$ telescope. The extinction corresponds to a chord of $29 \mathrm{~km}$. Both Ida and Hirose are experienced lunar occultation 


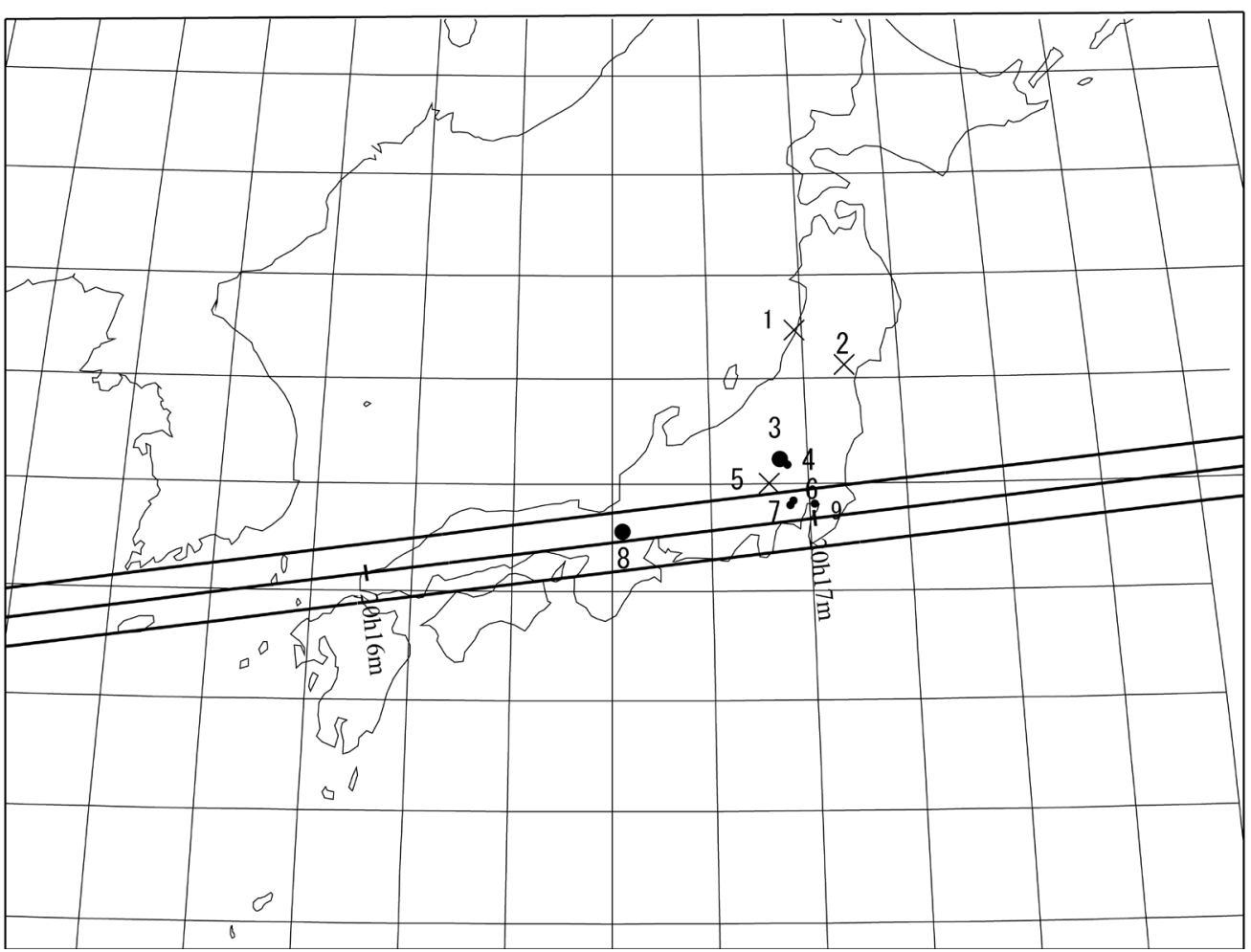

Figure 16. Occultation track and locations of observers of the occultation of HIP 052360 by (739) Mandeville on 1980 December 10. The black circle \#3 is visual timing site, and \#8 is an occultation from a site where no timing was observed. Crosses $(\# 1,2,5)$ indicate sites where no occultation took place and points $(\# 6,7,9)$ sites where clouds obscured any observation.

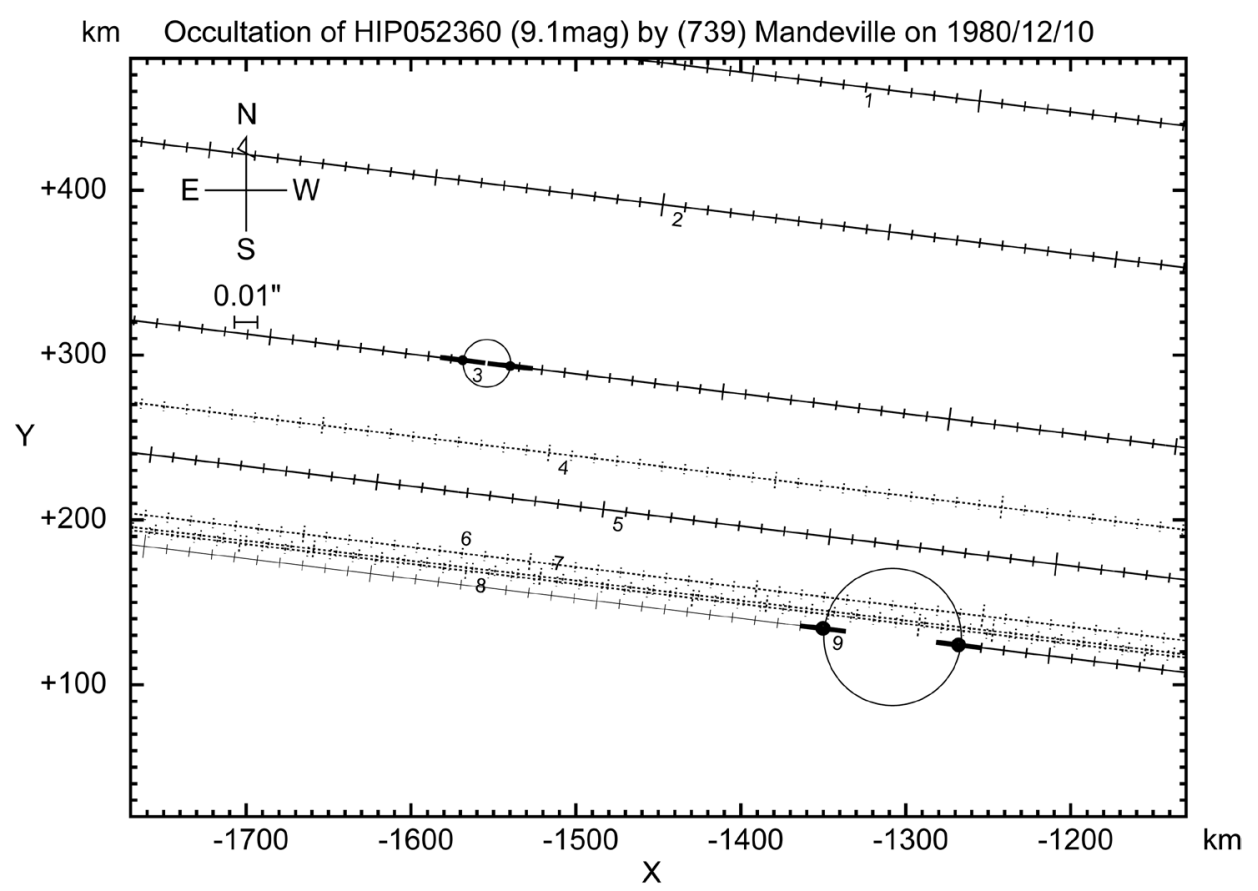

Figure 17. Result of the occultation of HIP 052360 by (739) Mandeville on 1980 December 10. Locations \#3 and \#8 are where visual occultation were timed but those times are inaccurate. But location \#5 between them was no occultation. 
Table 5. Observationdata od the occultation of PPM 157093 by (739) Mandeville on 1980 December 10. Geodetic datum is Tokyo Datum.

\begin{tabular}{|c|c|c|c|c|c|c|c|c|c|}
\hline No. & Observer & Location & longitude & latitude & height & telescope & method & phen & UTC \\
\hline 1 & Isao Satō & $\begin{array}{l}\text { Sakata, } \\
\text { Yamagata, } \\
\text { Japan }\end{array}$ & E13950'44.6" & N3855'32.8" & $4 \mathrm{~m}$ & $\begin{array}{c}13 \mathrm{~cm} \mathrm{~N} \\
\mathrm{~F}=7.7\end{array}$ & visual & & no occultation \\
\hline 2 & Sendai M. O. & $\begin{array}{c}\text { Sendai, } \\
\text { Miyagi, Japan }\end{array}$ & E140 $51 ' 56^{\prime \prime}$ & N38¹5'22" & $45 \mathrm{~m}$ & $\begin{array}{l}41 \mathrm{~cm} \mathrm{C}, \\
15 \mathrm{~cm} \mathrm{R}\end{array}$ & & & no occultation \\
\hline \multirow[t]{2}{*}{3} & Toshio Hirose & $\begin{array}{l}\text { Yaita, Tochigi, } \\
\text { Japan }\end{array}$ & E139²5'48.4" & N36 $27^{\circ} 37.7^{\prime \prime}$ & $260 \mathrm{~m}$ & $6.5 \mathrm{~cm} \mathrm{R}$ & visual & $\mathrm{D}$ & $\begin{array}{c}20 \mathrm{~h} 16 \mathrm{~m} \\
38.5 \mathrm{~s} \pm 1.0 \mathrm{~s}\end{array}$ \\
\hline & & & & & & & & $\mathrm{R}$ & $\begin{array}{c}20 \mathrm{~h} 16 \mathrm{~m} \\
40.6 \mathrm{~s} \pm 1.0 \mathrm{~s}\end{array}$ \\
\hline 4 & Kiyoshi Sakurai & $\begin{array}{c}\text { Tanuma, } \\
\text { Tochigi, Japan }\end{array}$ & E139³4'31.5" & N36²1'36.3" & $63 \mathrm{~m}$ & $12 \mathrm{~cm} \mathrm{~N}$ & & & cloudy \\
\hline 5 & Dodaira A.O. & $\begin{array}{c}\text { Tokikawa, } \\
\text { Saitama, Japan }\end{array}$ & E139¹1'42" & N3600'22" & $879 \mathrm{~m}$ & $91 \mathrm{~cm} \mathrm{C}$ & p.e. & & no occultation \\
\hline 6 & Yoshikazu Ogawa & $\begin{array}{c}\text { Nakano, } \\
\text { Tokyo, Japan }\end{array}$ & E13940'31.1" & N35 $41^{\prime} 01.6^{\prime \prime}$ & $40 \mathrm{~m}$ & $6.8 \mathrm{~cm} \mathrm{R}$ & & & cloudy \\
\hline 7 & Yoshihiro Musashi & $\begin{array}{c}\text { Kawasaki, } \\
\text { Kanagawa, } \\
\text { Japan }\end{array}$ & E139³6'15.0" & N35³5'34.5" & $31 \mathrm{~m}$ & $10 \mathrm{~cm} \mathrm{~N}$ & & & cloudy \\
\hline 8 & Shoji Kawana & $\begin{array}{c}\text { Chiba, Chiba, } \\
\text { Japan }\end{array}$ & $\mathrm{E} 140^{\circ} 06^{\prime} 04.1^{\prime \prime}$ & N35 4 41'01.6" & $16 \mathrm{~m}$ & $8 \mathrm{~cm} \mathrm{R}$ & & & cloudy \\
\hline 9 & Miyoshi Ida & $\begin{array}{l}\text { Ohmihachiman } \\
\text {, Shiga, Japan }\end{array}$ & E13611'53.3" & N3506'38.5" & $128 \mathrm{~m}$ & $6.5 \mathrm{~cm} \mathrm{R}$ & visual & $\mathrm{D}$ & $20 \mathrm{~h} 16 \mathrm{~m} 30 \mathrm{~s}$ \\
\hline & & & & & & & & $\mathrm{R}$ & $20 \mathrm{~h} 16 \mathrm{~m} 36 \mathrm{~s}$ \\
\hline
\end{tabular}

observers and they convinced the extinctions were real, but the timings were both visual in nature. However, Koichiro Tomita at Dodaira Station of the Tokyo Astronomical Observatory observed no occultation with a 91 $\mathrm{cm}$ reflector. The three observations are not consistent as is shown in Figure 17. A possible interpretation is duplicity of Mandeville, namely the extinction observed by Ida is by the primary body and the extinction observed by Hirose is by the secondary.

\section{Conclusion}

Possible satellites of (279) Thule, (324) Bamberga, (657) Gunlōd, (739) Mandeville, and duplicity of the primary body of the possible contact binary Trojan (624) Hektorare suggested from their stellar occultation and light curve observations. Confirmation is needed in order to verify of the nature of the observed extinctions.

\section{References}

[1] Neese, C., Ed. (2010) Asteroid Taxonomy V6.0. EAR-A-5-DDR-TAXONOMY-V6.0. NASA Planetary Data System.

[2] Zappala, V., Di Martino, M., Cellino, A., Farinella, P., De Sanctis, G. and Ferreri, W. (1989) Rotation Properties of Outer Belt Asteroids. Icarus, 82, 354-368. http://dx.doi.org/10.1016/0019-1035(89)90043-2

[3] Millis, R.L., Wasserman, L.H., Franz, O.G., Bowell, E., Nye, R.A., Thompson, D.T., White, N.M., Hubbard, W.B., Eplee Jr., R.E., Lebofsky, L.A., Marcialis, R.L., Greenberg, R.J., Hunten, D.M., Reitsema, H.J., Qian, B., Dunham, D.W., Maley, P.D., Klemola, A.R. and Yeomans, D.K. (1989) Observation of the 8 December 1987 Occultation of AG $+40^{\circ} 0783$ by 324 Bamberga. Astronomical Journal, 98, 1094-1099

[4] Gehrels, T. and Owings, D. (1962) Photometric Studies of Asteroids IX. Additional Light Curves. Astrophysical Journal, 135, 906-924. http://dx.doi.org/10.1086/147334 
[5] Scaltriti, F., Zappala, V., Stanzel, R., Blanco, C., Catalano, S. and Young, J.W. (1980) Lightcurves and phase relation of asteroid 324 Bamberga. Icarus, 43, 391-398. http://dx.doi.org/10.1016/0019-1035(80)90184-0

[6] Lagerkvist, C.I., Magnusson, P., Williams, I.P., Buontempo, M.E., Gibbs, P. and Morrison, L.V. (1989) Physical Studies of Asteroids. XIX-Phase Relations and Composite Lightcurves Obtained with the Carlsberg Meridian Circle. Astronomy \& Astrophysics Supplement Series, 78, 519-532.

[7] Satō I., Buie, M., Maley, P.D., Hamanowa, H., Tsuchikawa, A. and Dunham, D.W. (2014) A 3-D Shape of (704) Interamnia from Its Occultations and Lightcurves. International Journal of Astronomy and Astrophysics, 4, 91-118. http://dx.doi.org/10.4236/ijaa.2014.41010

[8] Marchis, F., Wong, M.H., Berthier, J., Descamps, P., Hestroffer, D., Vachier, F., Le Mignant, D.W.M. and de Pater, I. (2006) S/2006 (624) 1. IAU Circular No. 8732.

[9] Dunlap, J.L. and Gehrels, T. (1969) Minor Planet III. Lightcurves of a Trojan Asteroid. Astronomical Journal, 74, 796-803. http://dx.doi.org/10.1086/110860

[10] Hartmann, W.K. and Cruikshank, D.P. (1978) The Nature of Trojan Asteroid 624 Hektor. Icarus, 36, 353-366. http://dx.doi.org/10.1016/0019-1035(78)90114-8

[11] Zappala, V. and Knezevic, Z. (1984) Rotation Axes of Asteroids: Results for 14 Objects. Icarus, 59, 436-455. http://dx.doi.org/10.1016/0019-1035(84)90112-X

[12] Magnusson, P. (1986) Distribution of Spin Axes and Senses of Rotation for 20 Large Asteroids. Icarus, 68, 1-39. http://dx.doi.org/10.1016/0019-1035(86)90072-2

[13] Michalowski, T. (1988) Photometric Astronomy Applied to Asteroids: 6, 15, 43, and 624. Acta Astronomica, 38, 455468.

[14] Dahlgren, M., Fitzsimmons, A., Lagerkvist, C.-I. and Williams, I.P. (1991) Differential CCD Photometry of Dubiago, Chron and Hektor. Monthly Notice of the Royal Astronomical Society, 250, 115-118. http://dx.doi.org/10.1093/mnras/250.1.115

[15] De Angelis, G. (1992) New Asteroid Pole Determinations. In: Brahic, A., Gerard, J.-C. and Surdej, J., Eds., Observations and Physical Properties of Small Solar System Bodies, Universite de Liege, Institut d'Astrophysique, Liege, 195-201.

[16] Detal, A., Hainaut, O., Ibrahim-Denis, A., Pospieszalska-Surdej, A., Schils, P., Schober, H.J. and Surdej, J. (1994) Pole, Albedo and Shape of the Minor Planets 624 Hektor and 43 Ariadne: Two Tests for Comparing Four Different Pole Determination Methods. Astronomy \& Astrophysics, 281, 269-280.

[17] De Angelis, G. (1995) Asteroid Spin, Pole and Shape Determinations. Planetary Space Science, 43, 649-682. http://dx.doi.org/10.1016/0032-0633(94)00151-G

[18] Hainaut-Rouelle, M.-C., Hainaut, O.R. and Detal, A. (1995) Light Curves of Selected Minor Planets. Astronomy \& Astrophysics Supplement Series, 112, 125-142.

[19] Blanco, C. and Riccioli, D. (1998) Pole Coordinates and Shape of 30 Asteroids. Astronomy and Astrophysics Supplement Series, 131, 385-394. http://dx.doi.org/10.1051/aas:1998277

[20] Dunham, D.W., Herald, D., Frappa, E., Hayamizu, T., Talbot, J. and Timerson, B. (2014) Asteroid Occultations V12.0. EAR-A-3-RDR-OCCULTATIONS-V12.0. NASA Planetary Data System. 